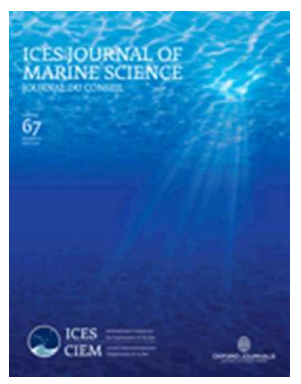

\title{
New approach for modelling bell-shaped size selectivity in shrimp trawl fisheries
}

\begin{tabular}{|r|l|}
\hline Journal: & ICES Journal of Marine Science \\
\hline Manuscript ID & ICESJMS-2017-079 \\
\hline Manuscript Types: & Original Article \\
\hline Date Submitted by the Author: & O6-Mar-2017 \\
\hline Complete List of Authors: & $\begin{array}{l}\text { Larsen, Roger; The Arctic University of Norway, Faculty of BioSciences, } \\
\text { Fisheries and Economics } \\
\text { Herrmann, Bent; SINTEF Fisheries and Aquaculture, Fishing Gear } \\
\text { Technology } \\
\text { Sistiaga, Manu; SINTEF Fisheries and Aquaculture, Fisheries Technology } \\
\text { Brinkhof, Jesse; UiT Norges arktiske universitet, The norwegian College of } \\
\text { Fisheries Sciences } \\
\text { Tatone, Ivan; University of Tromsø, Norwegian College of Fishery Science } \\
\text { Langard, Lise; Norwegian Directorate of Fisheries }\end{array}$ \\
\hline Keyword: & \begin{tabular}{l} 
Shrimps, Size selectivity, Nordmöre grid, Bycatch, Trawl fishery \\
\hline
\end{tabular} \\
\hline
\end{tabular}

SCHOLARONE ${ }^{m}$

Manuscripts 
1 New approach for modelling bell-shaped size selectivity in shrimp

\title{
2 trawl fisheries
}

3 Roger B. Larsen ${ }^{1 a^{*}}$, Bent Herrmann ${ }^{1,2^{*}}$, Manu Sistiaga ${ }^{2^{*}}$, Jesse Brinkhof ${ }^{1}$, Ivan Tatone ${ }^{1}$, and

$4 \quad$ Lise Langård ${ }^{3}$

$5{ }^{1}$ The Arctic University of Norway UIT, Hansine Hansens veg 18, 9019 Tromsø, Norway

$6{ }^{2}$ SINTEF Fisheries and Aquaculture, Brattørkaia 17C, N-7010 Trondheim, Norway

$7 \quad{ }^{3}$ Norwegian Directorate of Fisheries, Postbox 185 Sentrum, 5804 Bergen, Norway

$8 \quad{ }^{a}$ Corresponding author. Tf: +4777644536

$9 \quad{ }^{*}$ Equal authorship

10 E-mail address: roger.larsen@uit.no

\begin{abstract}
11 Abstract
12 Trawlers targeting shrimps often use a Nordmöre sorting grid ahead of a small mesh codend to avoid bycatch while efficiently catching the target species. However, small fish can pass through the grid and be retained in the codend. This makes the size selection processes in the trawl fishery targeting shrimps complex, and the size-dependent curve for both the shrimp and the bycatch species often exhibits a bell-shaped signature. In this study we developed a new model and a method to estimate this bell-shaped size selection in shrimp fisheries, conducted fishing trials in the Northeast Barents Sea, and applied the new method to quantify the combined size selection of the Nordmöre grid and codend for the deep water shrimp (Pandalus borealis) and two bycatch species. The size selectivity for the bycatch showed the 21 expected bell-shaped pattern with low retention probability of very small and larger fish, whereas certain sizes of juveniles had high retention probability. The smallest shrimps were released by the codend, and the Nordmöre grid had high passage probability for all sizes, although it decreased slightly for the largest shrimps.
\end{abstract}


25 Keywords: Shrimps; Size selectivity; Nordmöre grid; Bycatch; Trawl fishery.

\section{Introduction}

27 Shrimps are commercially important species, and they are fished all over the world. Although

28 the species and sizes targeted vary, in the majority of shrimp fisheries the selectivity of the gear is based on a grid followed by a size selective codend. This is the case for the deep water shrimp (Pandalus borealis) fisheries in the North Atlantic, which have used such selectivity devices since the early 1990 s.

Norway was the first country to use sorting grids to avoid bycatch of fish and other marine organisms in shrimp fisheries. The Nordmöre grid, first developed based on a device used to exclude jellyfish, proved to be efficient in excluding bycatch fish species during shrimp trawling (Isaksen et al., 1992). The Nordmöre grid consists of a guiding funnel, a 30-50 sloped grid, and a triangular fish outlet in the upper panel just in front of the grid. It was introduced in the Norwegian shrimp trawl fishery in the Barents Sea in the early 1990s and today is compulsory in several other shrimp fisheries around the world.

All vessels targeting shrimps in Norwegian waters are obliged to use a 19-mm bar spacing Nordmöre grid followed by a codend with a minimum mesh size of $35 \mathrm{~mm}$ (Norwegian Directorate of Fisheries, 2011). Thomassen and Ulltang (1975) tested several codend mesh sizes for the northern shrimp fisheries at the end of the 1960s and found that the retention lengths for deep water shrimps were acceptable with the 35-mm mesh size. Despite the many changes (larger gear, larger vessels, faster towing speed, etc.) in the northern shrimp fishery that have occurred since this investigation, the minimum codend mesh size remains at $35 \mathrm{~mm}$. The introduction of the Nordmöre grid eliminated the issue of bycatch of larger sizes of fish because they would not be able to pass through the grid into the trawl codend (Grimaldo and Larsen, 2005; Grimaldo, 2006). However, small-sized fish such as juveniles of various 
species are still able to pass through the grid and enter the codend together with the targeted

50

51

52 shrimps (He and Balzano, 2007, 2013).

Thus, several decades after the introduction of the Nordmöre grid in the shrimp fishery, concerns remain regarding the bycatch risk to juvenile fish. The current regulations of the Northeast Atlantic shrimp fishery allow retention of low numbers of juvenile fish from regulated species. For example, the fishing areas are closed if $10-\mathrm{kg}$ samples of shrimps exceed 8 cod (Gadus morhua) or 20 haddock (Melanogrammus aeglefinus), 3 redfish (Sebastes spp.), and 3 Greenland halibut (Reinhardtius hippoglossoides). Additionally, shrimp catches can contain no more than $10 \%$ by weight of undersized shrimps (i.e. $<15 \mathrm{~mm}$ carapace length) (Norwegian Directorate of Fisheries, 2011). These rather strict bycatch rules have led to frequent closures and openings of several large shrimp fishing grounds in the Northeast Atlantic over the years. The closures can last for weeks or months and cause huge operational problems and increased costs for the fishing fleet (i.e., the distances between potential fishing grounds become greater with increased area closures). Bycatches of juvenile fish and undersized shrimps also cause practical problems when sorting the catch onboard the fishing vessels.

The use of a Nordmöre sorting grid ahead of a small mesh codend makes the size selection processes in the trawl fishery targeting shrimps complex, and the size-dependent curve for both the shrimp and the bycatch species often exhibits a bell-shaped signature. However, a selection model that can properly describe and estimate these bell-shaped signature curves is not available, which implies a challenge to assess size selectivity in trawl fisheries targeting shrimps.

Considering the challenges described above, the aim of the current study was to:

- Develop a new model and a method to estimate bell-shaped size selection in shrimp fisheries using a Nordmöre grid followed by a small mesh size selective codend. 
- Quantify in detail the size selection of juveniles of some of the most important fish species frequently caught in the North Atlantic deep water shrimp fishery.

- Quantify the size selectivity for the targeted deep water shrimp of the mandatory selection system consisting of a 19-mm bar spacing Nordmöre grid followed by a 35-mm mesh size diamond mesh codend.

\section{Materials and Methods}

\section{Research vessel, study area, and experimental design}

The fishing trials were conducted using a selection system composed of a Nordmöre grid followed by a size selective codend. The bar spacing in the Nordmöre grid was measured with a caliper to be $18.8 \pm 0.4 \mathrm{~mm}$ (mean $\pm \mathrm{SD}$ ) following the procedure described in Wileman et al. (1996). The meshes in the codend were measured to be $33.8 \pm 1 \mathrm{~mm}$ (mean $\pm \mathrm{SD}$ ) using an ICES gauge following the same procedure.

In order to independently assess the contribution of the grid and the codend to the overall selectivity of the gear, the shrimps and fish released by the grid and the codend could be collected separately using two independent covers: one over the opening of the grid and the other one over the codend. Such double cover setups have been used previously to collect selectivity data in fish fishery studies (e.g., Sistiaga et al., 2010). However, the meshes in a shrimp codend are already small, which increases the risk that the cover with even smaller mesh size will affect the selectivity in the codend. This is mainly related to the substantial reduction in water flow created by the small meshes that would have to be used over a shrimp codend and to the risk of a masking effect. In addition, using two covers makes the whole gear setup more complicated (e.g., the covers can become entangled). Therefore, we used two different experimental setups during the sea trials. In the test haul setup, we fished with a Nordmöre grid followed by a selective codend. In those hauls a small-meshed cover (mesh 
size $16.4 \pm 0.5 \mathrm{~mm}($ mean $\pm \mathrm{SD})$ ) collected fish and shrimps escaping from the opening in

front of the Nordmöre grid and no cover was used over the codend (Fig. 1). In the control haul setup, the codend contained a small-meshed inner net (mesh size $18.5 \pm 0.9 \mathrm{~mm}(\mathrm{mean} \pm \mathrm{SD})$ ) installed with a low hanging ratio to prevent fish and shrimps from escaping through the codend. In this setup, the fish and shrimps that escaped in front of the Nordmöre grid were collected in a small-meshed cover (mesh size $18.9 \pm 1.2 \mathrm{~mm}$ (mean \pm SD)) (Fig. 1). Test and control hauls were conducted in the same fishing area during the same cruise.

The catch data from these groups of hauls were applied together to estimate the size selectivity for deep water shrimps and for the investigated bycatch species for the combined size selection system consisting of a Nordmöre grid and a size selective codend. For test hauls, the catch was collected in the test grid cover (GT) and in the test codend (CT), whereas for control hauls, the catch was collected in the control grid cover (GC) and in the blinded codend (CC). For each haul, the catches in the compartments GT and CT for test hauls and GC and $\mathrm{CC}$ for control hauls were sorted by species, length measured, and sorted into 1-cm wide length groups for fish and 1-mm wide length groups for shrimps. Thus, the catch data consisted of count numbers $(n)$ representing the number of individuals of the different species collected in each of the compartments. The total length of the fish was measured using a measuring board, and the carapace length of the shrimps was measured using a caliper.

FIG. 1 
123 alternated. Thyboron $\mathrm{T} 2\left(6.5 \mathrm{~m}^{2}\right.$ and $\left.2200 \mathrm{~kg}\right)$ trawl doors were used, and an 8-m long rope 124 was linked between the warps $80 \mathrm{~m}$ in front of the doors, which kept the distance between the 125 doors at 48-52 $\mathrm{m}$ during the tows. The Campelen trawl has a $19.2 \mathrm{~m}$ fishing line and is 126 believed to work at its optimal wingspread (ca. $15 \mathrm{~m}$ ) and height (ca. $6.5 \mathrm{~m})$ when the door 127 distance is kept in this range. We used $40 \mathrm{~m}$ double sweeps and a $19.2 \mathrm{~m}$ long rockhopper 128 gear built of three sections with $46 \mathrm{~cm}$ rubber discs.

129 Both trawls were equipped with 4-panel Nordmöre grid sections that are equivalent in 130 dimensions and construction to the 2-panel standard Nordmöre grid section used by the 131 Norwegian coastal fleet targeting shrimp. The Nordmöre grid in such a section is made of 132 stainless steel and is $1510 \mathrm{~mm}$ high and $1330 \mathrm{~mm}$ wide. The grid in both sections used was 133 mounted so that it would maintain an angle of $45 \pm 2.5^{\circ}$ while fishing.

\section{Model for size selection}

135 The size selection system consists of two main parts:

136 i) The first part is a Nordmöre grid, which the fish and shrimps must pass through to enter the codend. If they do not pass through this grid they are released during this first part of the selection process. To pass through the grid, two conditions need to be fulfilled: a) they need to contact the grid and b) morphologically they must be able to pass through the grid, which is dependent on their size and orientation when they come in contact with the grid.

ii) The second part is a codend that collects the fish and shrimps that pass through the grid. The codend is also size selective, and its size selection is the second part of the combined selection process.

Thus, for a fish or deep water shrimp to be retained in the codend $\left(r_{\text {combined }}(l)\right)$, it must be 
147 second process $\left.\left(r_{\text {codend }} l\right)\right)$, meaning being held in the codend. Therefore, the combined size

148 selection of the process can be modeled by:

$149 r_{\text {combined }}(l)=r_{\text {grid }}(l) \times r_{\text {codend }}(l)(1)$

150 where $l$ denotes the length of the fish or the length of the shrimp carapace. This system can be 151 defined as a sequential dual selection system. It is a dual system because it consists of two 152 processes and it is sequential because the second process follows the first.

153 The next step is to model each of the two size selection processes individually. For the 154 first process, we need to consider that some fish or shrimps might not contact (see Larsen et 155 al., 2016 for the explanation of contact in this context) the Nordmöre grid at all or that they 156 might do so with such a poor orientation that they have no length-dependent chance of 157 passing though the grid. This is modeled by the length-independent parameter $C_{\text {grid. }} C_{\text {grid }}$ has a 158 value in the range 0.0 to 1.0 , where 1.0 means that every individual of the species contacts the 159 grid in a way that gives it a length-dependent chance of passing through the grid. For an 160 individual contacting the grid with sufficiently good orientation to give it a length-dependent 161 chance of passing through grid $\left(\right.$ rcontact $\left._{\text {grid }}(l)\right)$, the following logit model was used:

$\operatorname{rcontact}_{\text {grid }}\left(l, L 50_{\text {grid }}, S R_{\text {grid }}\right)=1.0-\operatorname{logit}\left(l, L 50_{\text {grid }}, S R_{\text {grid }}\right)$

163 Model (2) considers that the probability of being able to pass through the grid is length 164 dependent and will decrease for larger individuals. $L 50_{\text {grid }}$ denotes the length of fish or shrimp 165 with $50 \%$ probability of being retained, and $S R_{\text {grid }}$ (selection range) describes the difference in 166 length between fish or shrimp with $75 \%$ and $25 \%$ probability of being retained, respectively.

167 Based on the above, the following model was used for the size selection in the first 168 process $\left(r_{1}(l)\right)$ :

$169 r_{\text {grid }}\left(l, C_{\text {grid }}, L 50_{\text {grid }}, S R_{\text {grid }}\right)=C_{\text {grid }} \times\left(1.0-\operatorname{logit}\left(l, L 50_{\text {grid }}, S R_{\text {grid }}\right)\right)$ 
170 The escape probability through the outlet in front of the Nordmöre grid was therefore 171 modeled by:

172

$$
\begin{aligned}
& e_{\text {grid }}\left(l, C_{\text {grid }}, L 50_{\text {grid }}, S R_{\text {grid }}\right)=1.0-r_{\text {grid }}\left(l, C_{\text {grid }}, L 50_{\text {grid }}, S R_{\text {grid }}\right)=1.0-C_{\text {grid }}+ \\
& C_{\text {grid }} \times \operatorname{logit}\left(l, L 50_{\text {grid }}, S R_{\text {grid }}\right)
\end{aligned}
$$

174 For the second process (i.e., codend size selection), we assumed that the retention 175 probability can be modeled by a logit model (see Wileman et al. 1996 for further information 176 about the logit model):

$$
r_{\text {codend }}\left(l, L 50_{\text {codend }}, S R_{\text {codend }}\right)=\operatorname{logit}\left(l, L 50_{\text {codend }}, S R_{\text {codend }}\right)
$$
model:

$$
\begin{aligned}
& r_{\text {combined }}\left(l, C_{\text {grid }}, L 50_{\text {grid }}, S R_{\text {grid }}, L 50_{\text {codend }}, S R_{\text {codend }}\right)= \\
& C_{\text {grid }} \times\left(1.0-\operatorname{logit}\left(l, L 50_{\text {grid }}, S R_{\text {grid }}\right)\right) \times \operatorname{logit}\left(l, L 50_{\text {codend }}, S R_{\text {codend }}\right)
\end{aligned}
$$

Model (6) is a so-called structural model because it is based on modeling the individual processes expected to be involved in the combined size selection in the system. One advantage of applying a structural model compared to an empirical-based model is that once the values of the parameters in the model are estimated, they can be applied to investigate not only the combined processes in the system but also the individual processes. In this context, each of the model parameter values obtained can be directly interpreted.

In the case of model (6), five parameters need to be estimated to be able to describe the size selection in the system: $C_{\text {grid }}, L 50_{\text {grid }}, S R_{\text {grid }}, L 50_{\text {codend, }}$ and $S R_{\text {codend. }} C_{\text {grid }}$ loosely models the contact probability with the grid for modes of orientation that result in a length-dependent probability for an individual to pass through the grid. If all individuals contact the grid with a reasonable mode of contact, then the value for $C_{\text {grid }}$ should be 1.0. However, this is not 
necessarily the case, as some individuals may escape through the escape outlet in front of the

Nordmöre grid (Fig. 1) without contacting the grid first. Other individuals may be so poorly orientated when they meet the grid that the probability of them passing through will be similar to those not contacting the grid, which will also be reflected in the value of $C_{\text {grid. }}$. Thus, $L 50_{\text {grid }}$ and $S R_{\text {grid }}$ are respectively the L50 and SR values for individuals contacting the grid with a reasonable mode of orientation. $L 50_{\text {codend }}$ and $S R_{\text {codend }}$ are the L50 and SR values for the codend selection (Fig. 1). As different species have different morphology and behavior, values of the parameters $C_{\text {grid }}, L 50_{\text {grid }}, S R_{\text {grid }}, \mathrm{L} 50_{\text {codend, }}$ and $S R_{\text {codend }}$ for the same combined system will be species specific. Therefore, the analysis was applied separately for the different fish species and for the deep water shrimps.

\section{Data analysis and parameter estimation}

Catch data were collected in two groups. One of the groups consisted of control hauls obtained by summing compartments GC and CC (Fig. 1). Together, they sampled the size and species composition of fish entering the selective parts of the trawl (Nordmöre grid and codend), and in this respect the control hauls can be paired with the test hauls so that a pairedgear estimation method can be used (Wileman et al., 1996). However, compared to the standard paired-gear method in which none of the selective parts of the system uses covers to collect fish or shrimps escapees, our test hauls are special because they use a cover (GT) to collect fish and shrimps escaping ahead of the Nordmöre grid. Therefore, our experimental data collection design represents a combination of the paired and covered data collection and estimation methods (Wileman et al., 1996).

To estimate the average size selection of the test setup with pooled data, we paired them with the pooled control hauls. Based on this approach, the experimental data in the analysis were treated like three compartment data. Fish or shrimp caught were observed in GT, GC, or $(\mathrm{GC}+\mathrm{CC})$. For the estimation based on the size selection model established in section 2.2, 
218 we needed to express the probabilities that fish or shrimps of a specific length $l$ would be

219 observed in each of these three compartments conditioned they were caught. The probability

220 that the fish or shrimps would enter the selection section in one of the test hauls and in one of

221 the control hauls was modeled by the split factor, $S P$, as is traditionally done for paired-gear

222 data analysis (Wileman et al., 1996). This means that the probability that a fish or shrimp will

223 enter the test haul is $S P$, whereas the probability of them entering the control haul is $1.0-S P$.

224 All fish or shrimps entering the control haul are retained because both the cover over the grid

225 outlet and the blinded codend retain all potential escapees. For a fish or shrimp entering one

226 of the hauls included in the analysis (test or control), the probability that it will be retained in

227 the cover in front of the Nordmöre grid in one of the test hauls would, based on equation (4),

228 be $S P \times e_{\text {grid }}\left(l, C_{\text {grid }}, L 50_{\text {grid }}, S R_{\text {grid }}\right)$. For a fish or shrimp entering one of the hauls

229 included in the analysis, the probability that it will be retained in the codend of a test haul

230 would, based on equation (6), be

231

232

probability $\gamma$ that a fish or shrimp entering one of the test or control hauls will be observed in one of the three compartments $(\mathrm{GT}, \mathrm{GC}$, or $\mathrm{GC}+\mathrm{CC})$ can be expressed as:

234

$\gamma\left(l, C_{\text {grid }}, L 50_{\text {grid }}, S R_{\text {grid }}, L 50_{\text {codend }}, S R_{\text {codend }}, S P\right)=$

$S P \times e_{\text {grid }}\left(l, C_{\text {grid }}, L 50_{\text {grid }}, S R_{\text {grid }}\right)+$

$S P \times r_{\text {combined }}\left(l, C_{\text {grid }}, L 50_{\text {grid }}, S R_{\text {grid }}, L 50_{\text {codend }}, S R_{\text {codend }}\right)+1.0-S P$

237 Based on equation (7) and the considerations above, the probabilities $p_{G T}, p_{C T}$, and $p_{G C+C C}$ that

238 a fish or shrimp observed in the catch will be found in compartment GT, CT, or GC+CC, 239 respectively, can be expressed by: 


$$
\begin{aligned}
& p_{G T}\left(l, C_{\text {grid }}, L 50_{\text {grid }}, S R_{\text {grid }}, L 50_{\text {codend }}, S R_{\text {codend }}, S P\right)=\frac{S P \times e_{\text {grid }}\left(l, C_{\text {grid }}, L 50_{\text {grid }}, S R_{\text {grid }}\right)}{\gamma\left(l, C_{\text {grid }}, L 50_{\text {grid }}, S R_{\text {grid }}, L 50_{\text {codend }}, S R_{\text {codend }}, S P\right)} \\
& p_{C T}\left(l, C_{\text {grid }}, L 50_{\text {grid }}, S R_{\text {grid }}, L 50_{\text {codend }}, S R_{\text {codend }}, S P\right)=\frac{S P \times r_{\text {combined }}\left(l, C_{\text {grid }}, L 50_{\text {grid }}, S R_{\text {grid }}, L 50_{c o d e n d}, S R_{c o d e n d}\right)}{\gamma\left(l, C_{\text {grid }}, L 50_{\text {grid }}, S R_{\text {grid }}, L 50_{c o d e n d}, S R_{c o d e n d}, S P\right)} \\
& p_{G C+C C}\left(l, C_{\text {grid }}, L 50_{\text {grid }}, S R_{\text {grid }}, L 50_{\text {codend }}, S R_{\text {codend }}, S P\right)=\frac{1.0-S P}{\gamma\left(l, C_{\text {grid }}, L 50_{\text {grid }}, S R_{\text {grid }}, L 50_{\text {codend }}, S R_{\text {codend }}, S P\right)}
\end{aligned}
$$

By using equation (8), the values for the parameters in the selection model (6) can be estimated from the collected experimental data by minimizing the following function with

$\left.\left.\left.\frac{n C C_{l j}}{q C C_{j}}\right) \times \ln \left(p_{G C+C C}\left(l, C_{\text {grid }}, L 50_{\text {grid }}, S R_{\text {grid }}, L 50_{\text {codend }}, S R_{\text {codend }}, S P\right)\right)\right]\right\}$

where the outer summation is over length classes $l$ in the experimental data and the inner summation is over experimental fishing hauls $i$ (from 1 to $a$ ) and $j$ (from 1 to $b$ ) with, respectively, the test and control setup. $n G T_{l i}, n C T_{l i}, n G C_{l j}$, and $n C C_{l j}$ are the number of fish

251 or shrimps length measured of length class $l$ in haul $i$ and $j$ in the respective compartment, with $q G T_{i}, q C T_{i}, q G C_{j}$, and $q C C_{j}$ being the corresponding sampling factors (i.e., the fraction of the catch that was length measured). Minimizing (9) with respect to the parameters in it is the same as maximizing the likelihood for the observed experimental data, assuming that the formulated model (8) describes the experimental data sufficiently well. The observed experimental data sharing rates among the three compartments of the data, which model (8) is expected to describe, are given by: 


$$
p_{G T_{l}}=\frac{\frac{n G T_{l}}{q G T}}{\frac{n G T_{l}}{q G T}+\frac{n C T_{l}}{q C T}+\frac{n G C_{l}}{q G C}+\frac{n C C_{l}}{q C C}}
$$

258

$$
p_{C T_{l}}=\frac{\frac{n C T_{l}}{q C T}}{\frac{n G T_{l}}{q G T}+\frac{n C T_{l}}{q C T}+\frac{n G C_{l}}{q G C}+\frac{n C C_{l}}{q C C}}
$$

$p_{G C+C C_{l}}=\frac{\frac{n G C_{l}}{q G C}+\frac{n C C_{l}}{q C C}}{\frac{n G T_{l}}{q G T}+\frac{n C T_{l}}{q C T}+\frac{n G C_{l}}{q G C}+\frac{n C C_{l}}{q C C}}$

Due to the experimental procedure followed, there was no obvious way to pair the data from the individual test and control hauls. Hence, to estimate the mean selectivity parameters for the experimental gear, the raised length frequency data of the corresponding test hauls were combined and compared with the combined data from the control hauls as formulated in function (9). The confidence limits for the parameters and curves for the size selection model were estimated using a double bootstrapping method that accounts for the uncertainty resulting from this unpaired nature of the data collection. For this, we adopted and further generalized the method for estimating uncertainty in size selectivity based on unpaired trawl data described by Sistiaga et al. (2016). This procedure accounts for between-haul variation (Fryer, 1991) by selecting $a$ hauls with replacement from the test hauls and $b$ hauls with replacement from the control hauls during each bootstrap loop. Within-haul variability is accounted for by randomly selecting fish with replacement from each of the selected hauls for

271 each compartment separately, where the number selected from each compartment in each haul 272 is the same as the number sampled in that compartment in that haul. These data are then 273 raised and combined as described above, and the selectivity parameters are again estimated.

274 The additional uncertainty in the estimation caused by subsampling is automatically 275 accounted for by raising the data after the re-sampling (Eigaard et al., 2012). We performed 1000 bootstrap repetitions to calculate the Efron 95\% confidence limits (Efron, 1982;

277 Chernick, 2007) for the selection parameters.

278 The model's ability to describe the experimental data sufficiently well was evaluated 279 based on the p-value, model deviance versus degrees of freedom (DOF), inspection of how 
280 the model curve reflects the length-based trend in the data, and inspection of residual plots for 281 model deviation (Wileman et al., 1996). The analysis was carried out using the software 282 SELNET (Herrmann et al., 2012, 2013ab), which implements the models and the bootstrap 283 method described above.

\section{Results}

\section{Collected data}

286 We conducted 16 hauls during the trial, including 8 test hauls (Table 1) and 8 control hauls 287 (Table 2). The number of shrimps length measured during the cruise was of 4405 individuals. 288 Of the fish bycatch species, we measured 8773 American plaice (Hippoglossoides 289 platessoides) and 4439 redfish (Sebastes spp.).

290 TABLE 1

291 TABLE 2

\section{Size selectivity for shrimps}

293 The model used reflected the pattern observed in the experimental data well (Fig. 2). Thus, 294 although the p-value observed in the fit statistics was low, we are confident that the model 295 used represents the data adequately. All shrimps were estimated to make contact with the 296 Nordmöre grid, and most of them passed through it. However, the grid passage probability 297 was estimated to decrease slightly with increasing shrimp size. The codend selectivity showed 298 size-dependent release for shrimps with carapace length $<23 \mathrm{~mm}$, with only about $20 \%$ of the 299 shrimps with carapace length of $15 \mathrm{~mm}$ being retained by the codend. $L 50_{\text {codend }}$ was estimated 300 to be $17.72 \mathrm{~mm}$, and $S R_{\text {codend }}$ was estimated to be $3.63 \mathrm{~mm}$ (Table 3). $L 50_{\text {grid }}$ was $49.2 \mathrm{~mm}$, 301 which at first glance could seem meaningless because it is above the size range for this 302 species of shrimp (Table 3). However, this value is expected to be above a biologically 
303 meaningful value and confirms that most of the shrimps can pass through the grid except for

304 the slight decrease for large shrimps. The combined selectivity for the grid and codend 305 exhibited a slightly bell-shaped signature, with few shrimps $<15 \mathrm{~mm}$ being retained, a 306 maximum retention rate for shrimps with carapace length of $25 \mathrm{~mm}$, and a slight decrease for 307 shrimps above this size.

308 FIG. 2

309 TABLE 3

310 Size selectivity for American plaice

311 The model used reflected the pattern observed in the experimental data well (Fig. 3). Despite 312 the p-value being $<0.05$, the model used represents the data adequately and therefore we are 313 confident about the performance of the model. All American plaice were estimated to make 314 contact with the Nordmöre grid, and most of them passed through it. The grid passage 315 probability was very high for American plaice up to $12 \mathrm{~cm}$ long, followed by a monotonous 316 decrease and then very low passage probability for fish $>30 \mathrm{~cm}$ long. The codend only 317 showed low size selectivity for American plaice with an $L 50_{\text {codend }}$ value of $6.84 \mathrm{~cm}$, thus all 318 American plaice $>10 \mathrm{~cm}$ long that entered the codend were retained in it (Table 3). The 319 combined selectivity for the grid and codend showed a clear bell-shaped signature, with a 320 high retention probability for American place $\sim 10 \mathrm{~cm}$ long (ca. $90 \%$ retention). Retention of 321 individuals $<5 \mathrm{~cm}$ long was practically 0 and retention of fish in the range of 10 to $30 \mathrm{~cm}$ 322 decreased, with really low retention rates for fish $>30 \mathrm{~cm}$ long. In the range of 6 to $23 \mathrm{~cm}$, 323 retention probability for American plaice for the gear was $>25 \%$, meaning that this gear 324 would not be adequate in areas where the numbers of American plaice within this range are 325 high.

$326 \quad$ FIG. 3 


\section{Size selectivity for redfish}

328 For redfish, the model used represented the experimental data well up to $l=22 \mathrm{~cm}$ (Fig. 4).

329 Because fish above this size are outside the selective range of the gear, the model adequately 330 describes the size selection process in the gear. This upper limit is regarded as a consequence 331 of unequal entry of bigger redfish into the test and control gears. The combined size selection 332 showed a clear bell-shaped signature, with $>60 \%$ of redfish around $12 \mathrm{~cm}$ long being retained 333 by the gear but $<25 \%$ of redfish $<9 \mathrm{~cm}$ and $>15 \mathrm{~cm}$ long being retained. The grid passage 334 probability was high $(>80 \%)$ for redfish $<12 \mathrm{~cm}$ long, and it decreased monotonously, with 335 no redfish $>20 \mathrm{~cm}$ entering the codend. The codend size selection showed that none of the 336 redfish $>14 \mathrm{~cm}$ would be released by the codend and that $\mathrm{L}_{50}$ and $\mathrm{SR}_{2}$ were $9.8 \mathrm{~cm}$ and 1.7 $337 \mathrm{~cm}$, respectively (Table 3).

$338 \quad$ FIG. 4

\section{Discussion}

340 The bell-shaped size selection data resulting from the grid and codend configuration used in 341 this study were based on a new model and estimation method that is an extension of the 342 unpaired method described in Sistiaga et al. (2016). This new approach models the observed 343 data summed over hauls for a group of test and controls hauls, and it combines a structural 344 dual sequenced size selection model with unpaired data collection for groups of test and 345 control hauls. This model effectively described the length-dependent sharing of the observed 346 catch between the test codend, the test grid cover, and the control gear for all species 347 investigated. In addition to enabling estimation of the combined size selection for the 348 Nordmöre grid followed by the diamond mesh codend, this method enabled estimation of the 349 size selection for each of the selection devices individually because the structural model explicitly described the selectivity processes in each of the devices. Structural size selection 
351 models have previously been developed and applied to describe size selection in other trawl

352 fisheries. This includes models for fish sorting grids in combination with codends in finfish 353 fisheries (Sistiaga et al., 2010; Herrmann et al., 2013a), square mesh panels in combination 354 with selective codends (Zuur et al., 2001; O'Neill et al., 2006; Alzorriz et al., 2016), double 355 grid sorting devices (Larsen et al., 2016: Sistiaga et al., 2016), and excluding grids combined with a selective codend (Brčić et al., 2015; Stepputtis et al., 2015; Lövgren et al., 2016). Excluding grids combined with a selective codend result in the same bell-shaped selection pattern as the Nordmöre grid followed by a size selective codend. However, our study is the first time such a modelling process has been applied to a shrimp trawl fishery and the first time that a sequential model with two compartment data collection in test and control gears have been used. Our method is more complex than the methods previously applied, but it is necessary due to the practical problems that would have resulted from using a small mesh cover over the test codend.

The new method and model presented herein offer new possibilities for studying size selectivity in other shrimp fisheries. In particular, our approach enables detailed mapping of which sizes of bycatch species would have especially high risk of being caught if they are abundant in the shrimp fishing grounds.

In this study, we demonstrated the ability of the new model to represent bell-shaped selectivity data in detail for shrimp and two fish bycatch species: American plaice and redfish.

370 For the juvenile bycatch species, our results demonstrated very high and length-dependent 371 grid passage probability. Thus, in conjunction with the small-meshed diamond mesh codend used in the shrimp fishery, the gear has high catch risk for certain size ranges of these bycatch species. The use of the combined bycatch reducing and size selective system consisting of the

374 Nordmöre grid and $35 \mathrm{~mm}$ codend mesh is well established in the Northeast Atlantic shrimp 375 fishery. However, the data from our study clearly show that fish within a limited size range 
376 and undersized shrimps retained in the $35-\mathrm{mm}$ codend will continue to be a problem for the

377 northern shrimp fleet. If fish bycatch reduction and size selectivity of shrimp are to be

378 improved, the next research goal should be to address the mesh selection process in front of or

379 aft of the Nordmöre grid section, including the codend. On board the fishing vessels, crew

380 members seek simple and practical solutions to improve species separation in order to reduce

381 production (i.e., cleaning and grading the shrimp catches). From this point of view, sorting

382 devices based on flexible mesh panels are preferred.

383 Acknowledgements

384 We thank the crew of RV "Helmer Hanssen" and assistants Ingeborg Sætra, Hermann 385 Pettersen, Tomas Araya, and postdoctoral researcher André Frainer for valuable assistance on 386 board. We are grateful to the Arctic University of Norway UIT in Tromsø and the Norwegian 387 Seafood Research Fund for funding the experiments carried out in this study.

\section{References}

389
Alzorriz, N., Arrregi, L., Herrmann, B., Sistiaga, M., Casey, J., Poos, J.J., 2016. Questioning the effectiveness of implemented technical measures under the EU landings obligation: the Basque Otter Bottom Trawl fishery case study. Fish. Res. 175, 116-126. Doi: 10.1016/j.fishres.2015.11.023.

Brčić, J., Herrmann, B., Sala, A., 2015. Selective characteristics of a shark-excluding grid device in a Mediterranean trawl. Fish. Res. 172, 352-360. Doi: 10.1016/j.fishres.2015.07.035.

Chernick, M.R., 2007. Bootstrap Methods: A guide for practitioners and researchers, second edition. Wiley series in probability and statistics. Wiley, New York. ISBN 978-0-47175621-7. 
399 Efron, B., 1982. The jackknife, the bootstrap and other resampling plans. SIAM Monograph $400 \quad$ No 38, CBSM-NSF. ISBN: 978-0-89871-179-0.

401 Eigaard, O. R., Herrmann, B., and Nielsen, J. R. 2012. Influence of grid orientation and time 402 of day on grid sorting in a small-meshed trawl fishery for Norway pout (Trisopterus 403 esmarkii). Aqua. Liv. Res. 25, 15-26. Doi: 10.1051/alr/2011152.

404 Fryer, R.J., 1991. A model of between-haul variation in selectivity. ICES J. Mar. Sci. J. Cons. $405 \quad$ 48, 281-290. doi:10.1093/icesjms/48.3.281

406 Grimaldo, E., 2006. The effects of grid angle on a modified Nordmöre-grid in the Nordic 407 Shrimp Fishery. Fish. Res. 77, 53-59. Doi: 10.1016/j.fishres.2005.09.001.

408 Grimaldo, E., Larsen, R. B., 2005. The cosmos grid: A new design for reducing by-catch in 409 the Nordic shrimp fishery. Fish. Res. 76, 187-197. Doi: 10.1016/j.fishres.2005.06.010.

410 He, P., Balzano, V., 2007. Reducing the catch of small shrimps in the Gulf of Maine pink 411 shrimp fishery with a size-sorting grid device. ICES J. Mar. Sci., 64, 1551-1557. Doi: $412 \quad 10.1093 /$ icesjms/fsm098.

413 He, P., Balzano, V., 2013. A new shrimp trawl combination grid system that reduces small 414 shrimp and finfish bycatch. Fish. Res. 140, 20-27. Doi: 10.1016/j.fishres.2012.11.009. 415 Herrmann, B., Sistiaga, M. B., Nielsen, K. N., and Larsen, R. B. 2012. Understanding the size 416 selectivity of redfish (Sebastes spp.) in North Atlantic trawl codends. J. Northw. Atl. 417 Fish. Sci. 44, 1-13. Doi:10.2960/J.v44.m680.

418 Herrmann, B., Sistiaga, M., Larsen, R.B., Nielsen, K.N., 2013a. Size selectivity of redfish 419 (Sebastes spp.) in the Northeast Atlantic using grid-based selection systems for trawls. 420 Aquat. Living Resour. 26, 109-120. Doi: 10.1051/alr/2013051.

421 Herrmann, B., Sistiaga, M., Larsen, R.B., Nielsen, K.N., Grimaldo, E., 2013b. Understanding $422 \quad$ sorting grid and codend size selectivity of Greenland halibut (Reinhardtius 423 hippoglossoides). Fish. Res. 146, 59-73. Doi: 10.1016/j.fishres.2013.04.004. 
424 Isaksen, B., Valdemarsen, J.W., Larsen, R.B., Karlsen, L., 1992. Reduction of fish by-catch in 425 shrimp trawl using a rigid separator grid in the aft belly. Fish. Res. 13, 335-352.

427

428 doi:10.1016/0165-7836(92)90086-9.

Larsen, R.B., Herrmann, B., Sistiaga, M., Grimaldo, E., Tatone, I., Onandia, I., 2016. Size selection of redfish (Sebastes spp.) in a double grid system: Quantifying escapement through individual grids and comparison to former grid trials. Fish. Res. 183, 385-395. Doi: 10.1016/j.fishres.2016.07.013.

Lövgren, J., Herrmann, B., Feekings, J., 2016. Bell-shaped size selection in a bottom trawl: A case study for Nephrops directed fishery with reduced catches of cod. Fish. Res. 184, 26-35. Doi: 10.1016/j.fishres.2016.03.019.

Misund, R. pers. comm. Robert Misund, Senior adviser at the Norwegian Directorate of Fisheries, Mailbox 185 Centrum, 5804 Bergen, Norway.

Norwegian Directorate of Fisheries, 2011. J-209-2011: Forskrift om maskevidde, bifangst og minstemål m.m. ved fiske i fiskevernsonen ved Svalbard (In Norwegian).

O’Neill, F.G., Kynoch, R.J., Fryer, R.J., 2006. Square mesh panel in North Sea demersal trawls: separate estimates of panel and codend selectivity. Fish. Res. 78, 333-341. Doi: 10.1016/j.fishres.2005.12.012.

Thomassen, T. and Ulltang, Ø., 1975. Report from mesh selection experiments on Pandalus borealis in Norwegian waters. ICES CM 1975/K:51.

Sistiaga, M, Herrmann, B., Grimaldo, E., Larsen, R.B., 2010. Assessment of dual selection in grid based selectivity systems. Fish. Res. 105, 187-199. Doi: 10.1016/j.fishres.2010.05.006.

Sistiaga, M., Brinkhof, J., Herrmann, B., Grimaldo, Langård, L., Lilleng, D., 2016. Size selection performance of two flexible sorting grid section designs in the Northeast 
$448 \quad$ Arctic cod (Gadus morhua) and haddock (Melanogrammus aeglefinnus) fishery. Fish.

449 Res. 183, 340-351. Doi: 10.1016/j.fishres.2016.06.022.

450 Stepputtis, D., Santos, J., Herrmann, B., Mieske, B., 2015. Broadening the horizon of size

451 selectivity in trawl gears. Fish. Res. 184, 18-25. Doi: 10.1016/j.fishres.2015.08.030.

452 Wileman, D. A., Ferro, R. S. T., Fonteyne, R., and Millar, R. B. (Eds.), 1996. Manual of

453 methods of measuring the selectivity of towed fishing gears. ICES Cooperative

$454 \quad$ Research Report No. 215.

455 Zuur, G., Fryer, R.J., Ferro, R.S.T., Tokay, T., 2001. Modelling the size selectivities of a trawl

456 codend and an associated square mesh panel. ICES J. Mar. Sci. 58, 657-671. Doi:

$457 \quad 10.1006 / j m s c .2001 .1049$. 
Fig. 1: Experimental design: with separate group of hauls with test gear (top) and control gear (bottom). $338 \times 190 \mathrm{~mm}(96 \times 96 \mathrm{DPI})$ 
Fig. 2: Size selectivity plots for shrimps. The left column shows the fit of the selection model (8) to the experimental catch sharing rates (10). Plot "a" shows the length dependent share of shrimps found in the grid cover of the test gear, plot "b" shows the length dependent length of shrimps found in the control gear, and plot " $c$ " shows the length dependent share of shrimps observed in the codend of the test gear. The plots in the right column show the selectivity curves for the test gear with plot "d" showing the length dependent grid passage probability (4), plot "e" showing the length dependent codend selectivity in the test gear (5), and plot "f" showing the combined size selectivity of the Nordmöre grid and the codend for the test gear (6).

$305 \times 308 \mathrm{~mm}(96 \times 96$ DPI) 
Fig. 3: Size selectivity plots for American plaice. The left column shows the fit of the selection model (8) to the experimental catch sharing rates (10). Plot "a" shows the length dependent share of American plaice found in the grid cover of the test gear, plot " $b$ " shows the length dependent length of American plaice found in the control gear, and plot " $\mathrm{c}$ " shows the length dependent share of American plaice observed in the codend of the test gear. The plots in the right column show the selectivity curves for the test gear with plot "d" showing the length dependent grid passage probability (4), plot "e" showing the length dependent codend selectivity in the test gear (5), and plot "f" showing the combined size selectivity of the Nordmöre grid and the codend for the test gear (6).

\section{$305 \times 308 \mathrm{~mm}(96 \times 96 \mathrm{DPI})$}


Fig. 4: Size selectivity plots for redfish. The left column shows the fit of the selection model (8) to the experimental catch sharing rates (10). Plot "a" shows the length dependent share of redfish found in the grid cover of the test gear, plot "b" shows the length dependent length of redfish found in the control gear, and plot " $c$ " shows the length dependent share of redfish observed in the codend of the test gear. The plots in the right column show the selectivity curves for the test gear with plot "d" showing the length dependent grid passage probability (4), plot "e" showing the length dependent codend selectivity in the test gear (5), and plot "f" showing the combined size selectivity of the Nordmöre grid and the codend for the test gear (6).

$305 \times 308 \mathrm{~mm}(96 \times 96$ DPI) 
2

1 TABLES

2 Table 1: Overview of the fish and shrimp length measured in the test hauls carried out during 3 the trials. The values in brackets represent the sampling factors. For the fish species there was 4 no subsampling.

\begin{tabular}{|c|c|c|c|c|c|c|c|c|c|c|c|c|}
\hline \multirow{2}{*}{$\begin{array}{c}\text { Haul } \\
\mathrm{Nr}\end{array}$} & \multirow{2}{*}{$\begin{array}{l}\text { Trawling } \\
\text { time } \\
\text { (min) }\end{array}$} & \multirow{2}{*}{$\begin{array}{l}\text { Depth } \\
\text { (m) }\end{array}$} & \multicolumn{2}{|c|}{ Shrimp } & \multicolumn{2}{|c|}{ American Plaice } & \multicolumn{2}{|c|}{ Redfish } & \multicolumn{2}{|c|}{ Cod } & \multicolumn{2}{|c|}{ Haddock } \\
\hline & & & GT (\% measured) & $\mathrm{CT}$ (\% measured) & GT & $\mathrm{CT}$ & $\mathrm{GT}$ & CT & $\mathrm{GT}$ & $\mathrm{CT}$ & $\mathrm{GT}$ & CT \\
\hline 9 & 60 & 268 & 150 (63.13\%) & 150 (1.34\%) & 391 & 283 & 211 & 42 & 38 & 14 & 19 & 18 \\
\hline 10 & 62 & 265 & $123(31.72 \%)$ & $146(0.94 \%)$ & 444 & 347 & 392 & 65 & 46 & 9 & 27 & 54 \\
\hline 11 & 64 & 268 & 98 (66.77\%) & 134 (1.05\%) & 482 & 402 & 494 & 108 & 114 & 22 & 63 & 135 \\
\hline 12 & 62 & 265 & $7(100 \%)$ & $121(2.10 \%)$ & 283 & 309 & 211 & 47 & 29 & 13 & 12 & 23 \\
\hline 13 & 63 & 274 & $21(100 \%)$ & 141 (1.76\%) & 239 & 212 & 354 & 91 & 26 & 22 & 23 & 26 \\
\hline 14 & 60 & 256 & $50(100 \%)$ & 161 (2.67\%) & 256 & 202 & 98 & 33 & 25 & 7 & 56 & 52 \\
\hline 15 & 63 & 252 & 75 (80.61\%) & $146(1.08 \%)$ & 230 & 320 & 135 & 82 & 117 & 23 & 40 & 133 \\
\hline 16 & 66 & 269 & 140 (8.18\%) & 167 (1.78\%) & 298 & 120 & 142 & 24 & 38 & 9 & 32 & 10 \\
\hline
\end{tabular}

5

6 
7 Table 2: Overview of the fish and shrimp length measured in the control hauls carried out

8 during the trials. The values in brackets represent the sampling factors. For the fish species

9 there was no subsampling.

\begin{tabular}{|c|c|c|c|c|c|c|c|c|c|c|c|c|}
\hline \multirow{2}{*}{$\begin{array}{c}\text { Haul } \\
\mathrm{Nr}\end{array}$} & \multirow{2}{*}{$\begin{array}{c}\text { Trawling } \\
\text { time } \\
\text { (min) }\end{array}$} & \multirow{2}{*}{$\begin{array}{l}\text { Depth } \\
\text { (m) }\end{array}$} & \multirow{2}{*}{$\begin{array}{r}\text { Shrimp } \\
\text { GC }\end{array}$} & \multirow[b]{2}{*}{ CC } & \multicolumn{2}{|c|}{ American Plaice } & \multicolumn{2}{|c|}{ Redfish } & \multicolumn{2}{|c|}{ Cod } & \multicolumn{2}{|c|}{ Haddock } \\
\hline & & & & & $\mathrm{GC}$ & $\mathrm{CC}$ & $\mathrm{GC}$ & $\mathrm{CC}$ & $\mathrm{GC}$ & CC & $\mathrm{GC}$ & $\mathrm{CC}$ \\
\hline 1 & 60 & 268 & $123(72.31 \%)$ & $160(1.63 \%)$ & 208 & 177 & 56 & 36 & 21 & 11 & 13 & 23 \\
\hline 2 & 61 & 257 & $120(58.14 \%)$ & 153 (1.95\%) & 238 & 182 & 143 & 37 & 17 & 8 & 20 & 10 \\
\hline 3 & 60 & 278 & $163(7.47 \%)$ & $173(1.16 \%)$ & 438 & 187 & 404 & 169 & 58 & 9 & 112 & 113 \\
\hline 4 & 60 & 271 & $108(9.60 \%)$ & $171(1.20 \%)$ & 265 & 156 & 184 & 86 & 12 & 7 & 36 & 38 \\
\hline 5 & 63 & 266 & $144(40.54)$ & 160 (1.91\%) & 321 & 121 & 108 & 20 & 28 & 9 & 22 & 15 \\
\hline 6 & 61 & 271 & $169(100 \%)$ & $175(2.02 \%)$ & 206 & 150 & 68 & 34 & 8 & 12 & 10 & 12 \\
\hline 7 & 60 & 271 & $208(22.74)$ & 169 (1.02\%) & 391 & 287 & 187 & 94 & 12 & 12 & 52 & 42 \\
\hline 8 & 63 & 272 & 189 (21.12) & 190 (0.73\%) & 327 & 301 & 164 & 120 & 18 & 12 & 33 & 72 \\
\hline
\end{tabular}

10

11 
12 Table 3: Size selectivity parameters and fit statistics results for shrimps, American plaice and 13 redfish based on fitting the model (8) to the experimental data. Values in () are $95 \%$ 14 confidence limits.

\begin{tabular}{|c|c|c|c|}
\hline & Shrimps & American Plaice & Redfish \\
\hline$\overline{C_{\text {grid }}}$ & $1.00(0.98-1.00)$ & $1.00(0.97-1.00)$ & $0.90(0.75-0-99)$ \\
\hline$L 5 O_{\text {grid }}(\mathrm{mm})$ & 49.17 (37.16 - 68.57) & $19.40(18.41-20.20)$ & $13.61(13.06-14.28)$ \\
\hline$S R_{\text {grid }}(\mathrm{mm})$ & $16.52(8.02-27.82)$ & $7.47(6.44-8.61)$ & $3.46(2.93-3.97)$ \\
\hline $\mathrm{LSO}_{\text {codend }}(\mathrm{mm})$ & $17.72-(16.10-22.59)$ & $6.84(5.46-7.68)$ & $9.78(8.85-10.45)$ \\
\hline$S R_{\text {codend }}(\mathrm{mm})$ & $3.63(1.79-9.45)$ & $1.66(0.10-2.66)$ & $1.74(1.33-2.60)$ \\
\hline$S P$ & $0.51(0.42-0.70)$ & $0.55(0.49-0.61)$ & $0.63(0.51-0.74)$ \\
\hline DOF & 34 & 90 & 54 \\
\hline Deviance & 175.66 & 118.38 & 101.91 \\
\hline$p$-value & $<0.0001$ & 0.0241 & 0.0001 \\
\hline
\end{tabular}

15

16 